\title{
MATERIALS AND EQUIPMENT FOR SURFACING OF METAL HOT CUTTING KNIVES
}

\author{
A.P. ZHUDRA ${ }^{1}$, A.P. VORONCHUK ${ }^{1}$, A.A. FOMAKIN ${ }^{1}$ and S.I. VELIKY ${ }^{2}$ \\ ${ }^{1}$ E.O. Paton Electric Welding Institute, NASU \\ 11 Bozhenko Str., 03680, Kiev, Ukraine. E-mail: office@paton.kiev.ua \\ ${ }^{2}$ EDTB of the E.O. Paton Electric Welding Institute \\ 11 Bozhenko Str., 03680, Kiev, Ukraine. E-mail: office@paton.kiev.ua
}

\begin{abstract}
Analysis of operation conditions of knives for hot cutting of metal was performed and the main types of their working edge wear were determined. Self-shielded flux-cored strip PL-Np-40Kh2N6G2S2M2FB (PLAN183) and specialized machine UD-298M were developed for automatic surfacing of blooming mill hot cutting knives. Process automation is conducted through application of SU-360 control system, which is based on modern components. Application of the new flux-cored strip and specialized surfacing machine allowed 2 to 3 times increase of surfacing efficiency. Here, surfaced knife resistance increased 1.5 to 2 times. This development has been successfully introduced at Company «Arselor Mittal Krivoj Rog». 5 Ref., 2 Figures.
\end{abstract}

Keywords: surfacing, surfacing technology, flux cored strip, knives for hot cutting, deposited metal, surfacing machine, wear resistance

Knives for hot cutting of metal in blooming mill shears are an important element in the technology of rolled blanks production. Their resistance is largely dependent on operating efficiency of the mill as a whole. Earlier, and in some enterprises even up to now, the knives for hot cutting of metal were made from $6 \mathrm{KhV} 2 \mathrm{~S}$ steel that is not cost-effective because of the high consumption of expensive metal.

Later on the technology of manufacturing knives from steel 45 has become widely applied, in which their working edges are surfaced by submerged-arc process with PP-Np-35V9Kh3SF flux-cored wire [1]. Good results were also obtained at surfacing by electric arc and electroslag processes with sintered electrode strips LS25Kh5FMS and LS-20Kh5FMS [2].

Surfacing is performed in three layers with blank preheating up to $670-720 \mathrm{~K}$, usually, in batch-produced equipment. After surfacing, the knife is placed into a thermostat for delayed cooling. Before polishing of working surfaces, the surfaced knife is subjected to high-temperature tempering at $900-930 \mathrm{~K}$.

This technology is quite practicable, but it has a number of disadvantages: low surfacing efficiency, absence of specialized equipment and insufficient resistance of surfaced knives.

All that necessitated performance of work on development of new surfacing materials, technology and equipment.

(c) A.P. ZHUDRA, A.P. VORONCHUK, A.A. FOMAKIN and S.I. VELIKY, 2015
Development of surfacing materials was based on analysis of knife operating conditions and kinetics of their working edge wear in operation. Knives for hot cutting of metal are operated under the conditions of metal-on-metal friction at high specific contact loads with abrupt temperature variations. In particular, at the moment of cutting the knife working edges contact the metal heated up to $1400-1500 \mathrm{~K}$, and the coolant is water. Cutting time is 5 to $9 \mathrm{~s}$, and the overall working cycle varies from 45 to $90 \mathrm{~s}$.

The process of wearing of knife working edges can be divided into three stages. Wear starts from fracture of small metal volumes at the cutting edge tip, when its shape is violated as a result of shearing and tearing out of microvolumes heated up to high temperatures. The leading factor here is plastic and diffusion interaction with the metal being cut.

The second wear stage is characterized by thermal and force action on the cutting edge and, consequently, by its rounding-off. The leading factor in this case is crushing with shear of cutting edge surface macrolayers that greatly promotes formation of thermal cracks in it. This period can be classified as mechanical wear under plastic deformation.

At the third stage, after reaching more than $6 \mathrm{~mm}$ rounding-off radius of cutting edge, working surface wear is due to breaking up of oxidized surface layer, its further corrosion and cracking, as well as contacting surface seizure in microlocal volumes at greatly changed pattern of thermal and force impact. The determinant aspect in this 


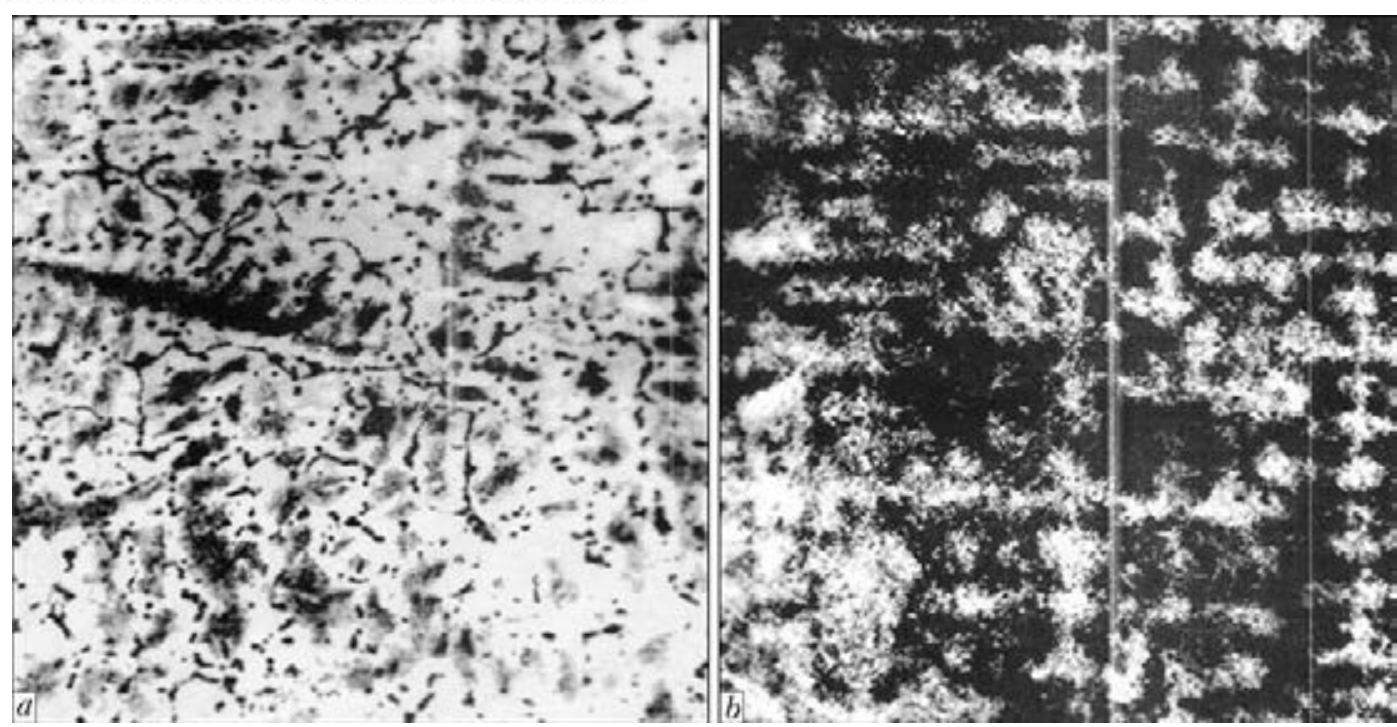

Figure 1. Microstructure $(\times 320)$ of $40 \mathrm{KhN6G2S2M} 2 \mathrm{FB}$ deposited layer before $(a)$ and after $(b)$ heat treatment

period, most probably, is corrosion-mechanical wearing.

Thus, the deposited metal should have good thermal resistance, as well as thermal shock resistance, ability to preserve its structure at heating and hardness, required to provide the working edge serviceability. It is known that heat-resistant tool steels have such a set of properties [3].

In development of new electrode material for surfacing hot cutting knives several types of deposited metal, namely 20Kh4V2M2, 30Kh4V2M2G2BFST, 40Kh2N6G2S2M2FB and 40Kh2N6K6M2G2SF were tested under the pilot-production conditions. Derived service and cost indices were the basis for selection of 40Kh2N6G2S2M2FB deposited metal. To obtain deposited metal of this type, self-shielded flux-

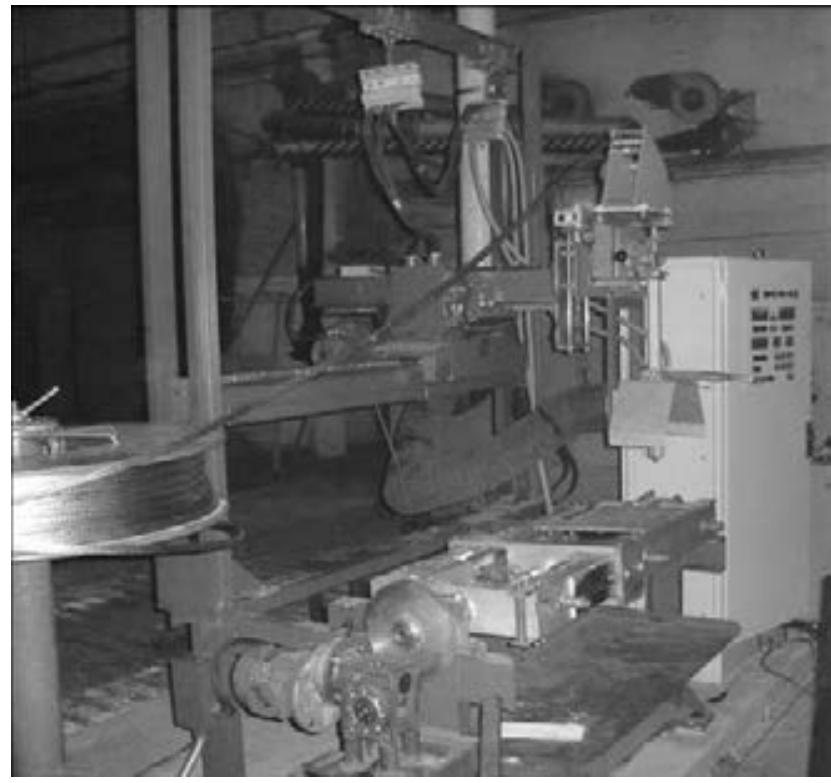

Figure 2. UD-298M machine for surfacing hot cutting knives cored strip was developed, which was later on named PL-AN183 [4, 5].

Structure of metal deposited with this fluxcored strip (Figure 1, $a$ ) consists of fine-needled martensite, residual austenite with a considerable quantity of excess phases in the form of carbides and intermetallics oriented, mainly, along the boundaries of grains $\left(H_{\mu}-550-610\right)$. After heat treatment (annealing-quenching-tempering) the deposited metal acquires the structure given in Figure 1, $b$. Deposited metal hardness after heat treatment is equal to $H R C$ 47-54.

An essential advantage of the proposed technology of open-arc surfacing with flux-cored strip is the high efficiency of process due to increase of parameters and reduction of the amount of deposited metal per knife. At surfacing of one of the typesizes of knives flux-cored wire consumption is $25 \mathrm{~kg}$ per knife, and at surfacing with self-shielded flux-cored strip PL-AN183 the same characteristic did not exceed $15 \mathrm{~kg}$. This was achieved due to more favourable formation of the deposited layer that enabled a marked reduction of allowances for further machining. Higher efficiency is also promoted by reduction of working time consumption for auxiliary operations, as operations related to slag crust removal, flux collection and sieving, were eliminated completely. All that on the whole allowed 2 to 3 times reduction of the time of one knife surfacing.

Technological advantages of flux-cored strip are the most completely implemented at application of specialized equipment - UD-298M surfacing machine (Figure 2) [4]. Process automation is performed due to application of SU-360 control system.

System of surfacing process control is based on modern components and consists of the following main parts: 
- programmable controller OMRON of CQM1H type with software for surfacing process control;

- frequency electric drives OMRON-YASKAWA for asynchronous motors (machine displacement and electrode feeding).

\section{Specification of UD-298M machine}

Rated mains voltage ( $50 \mathrm{~Hz}$ frequency), V

Maximum welding current, A ............ not more than 1000 Arc voltage, $\mathrm{V}$..................................... 26-38

Electrode strip feed rate, $\mathrm{m} / \mathrm{h}$............. not more than 40

Speed of surfacing head horizontal displacement

along the weld (smooth adjustment), $\mathrm{m} / \mathrm{h}$ $10-30$

Speed of surfacing head transverse displacement,

$\mathrm{m} / \mathrm{h}$

$2-100$

Maximum horizontal displacement of

surfacing head, mm ..................... not more than 1125

Maximum transverse displacement of

surfacing head, $\mathrm{mm} \ldots \ldots \ldots \ldots \ldots \ldots \ldots$ not more than 550

Maximum vertical displacement of surfacing

head, $m m$................................ not more than 300

Height of deposit center from floor level, mm ....... 800 820

Consumed power, kV.A ................. not more than 40

Surfaced knife dimensions, $\mathrm{mm}$ :

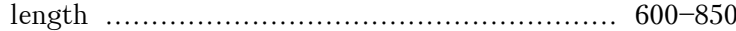

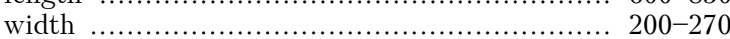

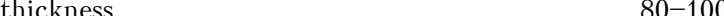

Weight of repaired knife, $\mathrm{kg}$.............. not more than 150

Machine overall dimensions, $\mathrm{mm}$ :

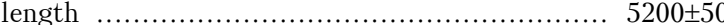

width ...................................... 2300 \pm 50

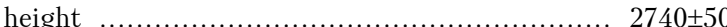

Weight, kg, not more than:

surfacing machine

740

control cabinet

Thus, the developed technology of open-arc surfacing of metal hot cutting knives with flux- cored strip, in combination with new equipment, allows hardening knife working edges in the automatic mode. Surfacing process efficiency is markedly increased. Time for surfacing a knife of average typesize $700 \mathrm{~mm}$ long is equal to about $2 \mathrm{~h}$, including auxiliary operations. Four working edges, each in three layers, are surfaced. Application of flux-cored strip PL-AN183 increases the hardened part resistance by 1.5 to 2 times, compared to knives surfaced by PP-Np-35V9Kh3SF wire. This development has been successfully introduced at Company «Arselor Mittal Krivoj Rog».

1. Paton, B.E. (1974) Technology of fusion electric welding of metals and alloys. Moscow: Mashinostroenie.

2. Malikin, V.L., Oparin, L.I. (1984) Service properties of metal of 5X4V2M2FS and 25X5FMS type deposited by electric arc and electroslag methods with sintered electrode strips. In: New processes of surfacing, properties of deposited metal and transition zone, 48-53. Kiev: PWI.

3. Geller, Yu.A. (1983) Tool steels. Moscow: Metallurgiya.

4. Zhudra, A.P., Voronchuk, A.P. (2010) Wear-resistant cladding by flux-cored strips. Svarshchik, 6, 6-9.

5. Zhudra, A.P., Voronchuk, A.P. (2012) Cladding flux-cored strips (Review). The Paton Welding J., 1, $34-38$.

Received 20.03.2015 